
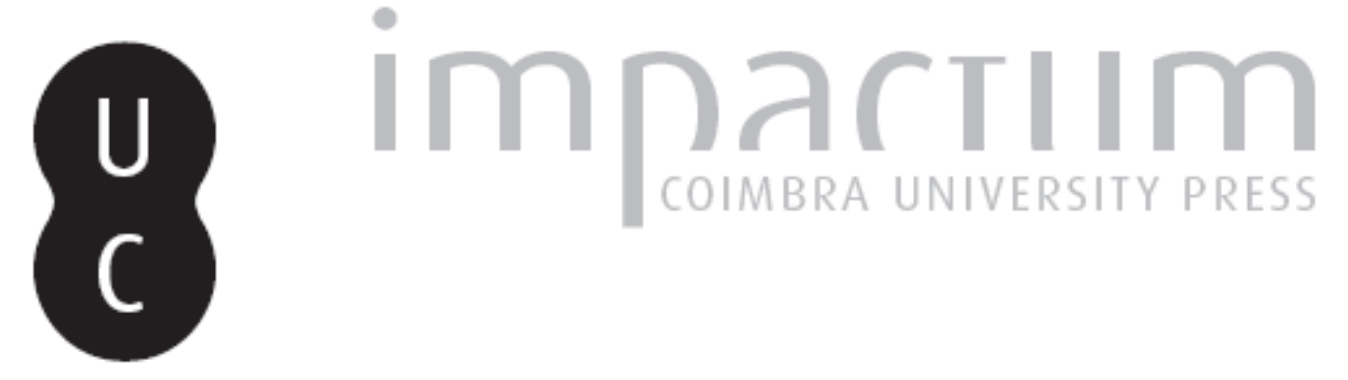

\title{
[Recensão a] West, M. L. - Indo-European poetry and myth
}

\author{
Autor(es): $\quad$ Rodrigues, Nuno Simões
}

Publicado por: Centro de História da Universidade de Lisboa

URL persistente:

URI:http://hdl.handle.net/10316.2/23943

DOI:

DOI:http://dx.doi.org/10.14195/0871-9527_18_29

Accessed : $\quad$ 26-Apr-2023 16:29:28

A navegação consulta e descarregamento dos títulos inseridos nas Bibliotecas Digitais UC Digitalis, UC Pombalina e UC Impactum, pressupõem a aceitação plena e sem reservas dos Termos e Condições de Uso destas Bibliotecas Digitais, disponíveis em https://digitalis.uc.pt/pt-pt/termos.

Conforme exposto nos referidos Termos e Condições de Uso, o descarregamento de títulos de acesso restrito requer uma licença válida de autorização devendo o utilizador aceder ao(s) documento(s) a partir de um endereço de IP da instituição detentora da supramencionada licença.

Ao utilizador é apenas permitido o descarregamento para uso pessoal, pelo que o emprego do(s) título(s) descarregado(s) para outro fim, designadamente comercial, carece de autorização do respetivo autor ou editor da obra.

Na medida em que todas as obras da UC Digitalis se encontram protegidas pelo Código do Direito de Autor e Direitos Conexos e demais legislação aplicável, toda a cópia, parcial ou total, deste documento, nos casos em que é legalmente admitida, deverá conter ou fazer-se acompanhar por este aviso.

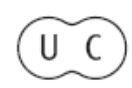



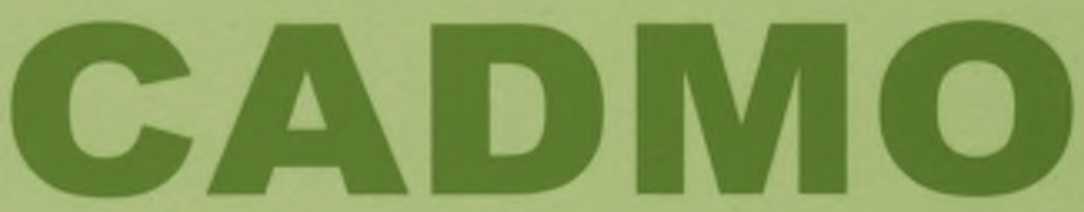

Revista de História Antiga

\author{
Centro de História \\ da Universidade de Lisboa
}

18

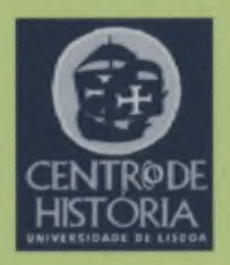

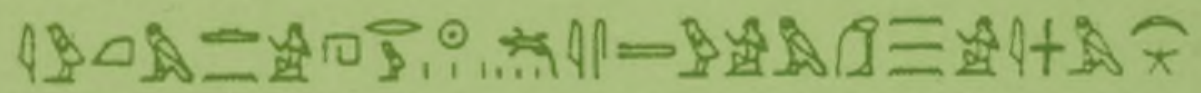

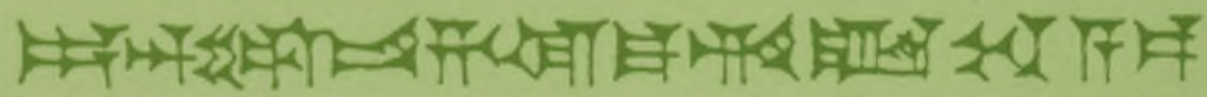

MHNIN AEI $\Delta$ E $\Theta E A ~ \Pi H \Lambda H I A \triangle E \Omega$ 
Sem descurar a riqueza do texto em aspectos antropológicos, etnográficos e religiosos, Ward defende que as Histórias são uma proposta de império, espiritual e intelectual, que Heródoto acreditava ser a única forma de unificar o mundo num único império e em simultâneo, preservar a diversidade cultural de todos os povos que o habitam. Democracia, oligarquia e monarquia são fruto abstracto da natureza complexa do discurso humano que recorre às palavras para universalizar aspectos particulares da natureza humana, como se torna evidente na leitura do famoso debate constitucional (Hdt., III.8083). Otanes, Megabizo e Dario, propõem cada um o que acreditam ser o melhor regime, na teoria. No entanto, nenhum deles toma em consideração as diferenças entre os povos, cujos costumes e culturas vão alterando com o passar do tempo. As ideias expressas no debate colocam o historiador de Halicarnasso como precursor da teoria politica que autores posteriores como Platão, Aristóteles, Xenofonte ou Políbio irão desenvolver nas suas obras ao estudarem as diferentes constituições que vigoravam por todo o mundo grego.

$O$ interessante estudo da $A$. encerra com uma curiosa reflexão sobre os perigos que rodeia a democracia americana nos alvores do século XXI, dedicando uma especial atenção ao problema do Império, num mundo profundamente mudado pelo 11 de Setembro. Com a guerra épica contra o terrorismo em pano de fundo, Ward reencena de forma magistral o debate constitucional ao confrontar as posições políticas e intelectuais, através dos discursos e entrevistas de três políticos (Paul Wolfowitz, Colin Powell, ambos da administração Bush e Joseph S. Nye Jr., que serviu durante a presidência de Clinton) e um jornalista, Robert W. Merry, que estuda o terrorismo e a projecção do poder americano no mundo, para nos demonstrar que apesar dos séculos decorridos, Heródoto mantém toda a sua actualidade e que os alertas que fez a Atenas continuam a ser válidos para a América e para as suas politicas externas.

\section{Nídia Catorze Santos}

M. L. WEST, Indo-European Poetry and Myth. Oxford, University Press, 2007, 525 pp., ISBN 978-0-19-928075-9.

Dez anos depois do importante The East Face of Helicon. West Asiatic Elements in Greek Poetry and Myth (Oxford, 1997), o Professor 
West brinda a comunidade científica com este livro, que continua e amplia em muito a investigação iniciada no primeiro. Se com a obra anteriormente publicada o A. tinha concretizado uma ruptura epistemológica, que há muito se sentia como necessária, designadamente ao nível dos estudos comparatistas no domínio da Antiguidade Pré-Clássica e Clássica, com esta nova empresa, M. L. West consolida a sua posição como o maior especialista actual neste domínio. Para isso, o A. recorre também, como seria de esperar, ao trabalho previamente apresentado por G. Dumézil, mas é igualmente inquestionável que poderia ter usufruído mais daquilo que $\mathrm{o}$ investigador francófono e a sua escola nos legaram.

Depois da difícil tarefa de analisar e tratar comparativamente as diferentes literaturas da Antiguidade (suméria, acádica, ugarítica, hebreo-aramaica, egípcia e grega), bem como as relações entre elas, o A. centra-se agora nas línguas e culturas radicadas no paradigma indo-europeu, bem como nas formas culturais em que aquelas se expressaram. I.e., depois de estabelecidos os paradigmas entre os eixos sumério, semítico, camítico e indo-europeu, West foca-se agora nas particularidades deste último. Mas também aqui, ganham particular importância as expressões mitológicas, que se confirmam como um dos meios privilegiados de expor o pensamento e a cultura de uma civilização. West tenta ir mais longe e detectar as raízes comuns dessas várias expressões culturais, através do método filológico comparativo. O resultado é um trabalho de elevadíssima erudição e rigor, só permitido e acessível a cientistas com uma formação histórico-linguístico-arqueológica como a de M. L. West. A título de exemplo, podemos referir que o A. domina, além do grego, como seria de esperar, o material indo-iraniano, ossético, celta (românico, gaélico, germânico e anglo-saxónico) e itálico.

West localiza os falantes de indo-europeu no tempo, no IV milénio a. C., e no espaço, na região entre o norte do mar Negro e o mar Cáspio (pp. 7-11). Partindo deste pressuposto, estabelece uma análise comparativa entre as culturas grega, iraniana, romana, indiana e anatólica, propondo cronologias de contacto e de síntese cultural. O A. assume que as semelhanças verificadas entre algumas das várias expressões religiosas e literárias deverão radicar numa origem comum e não em contactos de nível "horizontal" entre os protagonistas envolvidos. Mas isso poderá não se ter verificado em todos os casos. West deixa em aberto a possibilidade de ter existido também o contacto directo entre algumas dessas culturas, que terá permitido o 
câmbio de ideias e motivos. Esse poderá ter sido o caso, por exemplo, do binómio Grécia/Irão. De igual modo, possibilita-se ainda a discussão em torno da ideia de que o argumento da antiguidade de um motivo literário ou religioso poderá não ser determinante para definir a sua origem ou a sua prioridade. Confirma a sua difusão, mas confirmará a sua prioridade?

Todas as hipóteses avançadas por West merecem a sua atenção rigorosa, que as sustenta com material transcrito e análise filológica pormenorizada. Assim acontece com as partes que dedica a figuras do universo religioso e da cultura mitológica. Esta opção não implica que West se tenha preocupado em ser exaustivo, mas antes objectivo, preferindo chamar à colação os aspectos que pretende enfatizar o demonstrar. Talvez por isso sintamos falta de uma conclusão mais abrangente, que incluísse as ideias a que chegara com a publicação anterior, de modo a oferecer-nos uma visão de conjunto mais eficaz.

Qualquer crítica que Ihe possamos fazer, porém, é mínima, quando comparada com o resultado obtido e a importância conquistada e confirmada pelo Professor M. L. West com mais esta publicação. O livro inclui ainda um índice geral, mas falta-lhe um index locorum, que nos seria de grande utilidade, tendo em conta o valioso instrumento que é para a investigação.

Nuno Simões Rodrigues

SUSAN TREGGIARI, Terentia, Tullia and Publilia. The Women of Cicero's Family. New York, Routledge, 2007, 228 pp. ISBN 978-0-415-35179-9.

A obra agora apresentada faz parte de uma colecção que a Routledge em boa hora decidiu incluir o seu catálogo: Women of the Ancient World. Assim, depois de volumes dedicados a Olímpia, Cornélia, Júlia Augusti e Júlia Domna, chega-nos agora o texto de Susan Treggiari sobre as mulheres da família de Cícero.

Bastar-nos-ia ler o nome da Professora Treggiari na capa do livro para termos de imediato uma percepção da sua qualidade (a autora já nos deu provas disso em obras como Roman Freedmen during the Late Republic, publicado em 1969 e reeditado em 2000, Roman Marriage, publicado em 1991, e Roman Social History, de 2002). Mas a leitura do texto permite-nos a confirmação dessa primeira impressão. 